Motrivivência $\quad$ v. 27, n. 46 , p. 214-229, dezembro/2015

\title{
A PRODUÇÃO SOBRE JUVENTUDE EM PERIÓDICOS DA EDUCAÇÃO E EDUCAÇÃO FÍSICA
}

Jacqueline Zilberstein

Fabiano Bossle ${ }^{2}$

\section{RESUMO}

Este artigo de revisão visa analisar a abordagem do tema juventude nos periódicos nacionais das Áreas da Educação e da Educação Física. Foram analisados 148 periódicos referentes a estas Áreas. Identificamos que há maior produção sobre o tema juventude na Área da Educação, sendo que apenas 03 artigos, de um total de 52, faziam referência à Educação Física escolar. A partir disto, interpretamos que a baixa produção sobre este tema pode ser reveladora da pouca problematização sobre a temática da juventude e, também, de uma assimetria entre a pouca produção e os marcos legais da educação nacional que destacam a relevância da cultura juvenil que é compartilhada nas aulas de Educação Física nas escolas de Educação Básica.

Palavras-chave: Educação Física; Educação; Artigo de Revista; Juventude

1 Mestranda em Ciências do Movimento Humano. UFRGS, Porto Alegre/Rio Grande do Sul, Brasil. E-mail: jacquezilberstein@hotmail.com

2 Doutor em Ciências do Movimento Humano. Professor de graduação e pós-graduação da ESEF da UFRGS, Porto Alegre/Rio Grande do Sul, Brasil. E-mail: fabiano.bossle@ufrgs.br 


\section{INTRODUÇÃO}

Inicialmente sublinhamos que o artigo de Dias e Correia (2013) se constituiu em uma referência central para delimitar as possibilidades para avançar nas interpretações realizadas sobre a produção acadêmico-científica em periódicos nacionais sobre Educação Física no Ensino Médio. Para tanto, nosso foco foi analisar a produção acadêmico-científica sobre Educação Física no Ensino Médio e juventude nos periódicos nacionais da Educação e da Educação Física. Destarte, entendemos que o fenômeno "juventude" vem assumindo um papel de destaque em documentos que orientam a Educação no Brasil, principalmente no que se refere ao Ensino Médio.

No âmbito legislativo, de acordo com a Lei de Diretrizes e Bases da Educação Nacional (LDBEN) (BRASIL, 1996), o Ensino Médio é o nível de ensino no qual os estudantes deveriam consolidar e aprofundar os conhecimentos adquiridos no Ensino Fundamental. No Ensino Médio os alunos são preparados para o mundo do trabalho com noções de cidadania e capacidade de adaptação às possíveis novas realidades encontradas fora da escola, aprimoram-se como pessoa humana e compreendem processos produtivos. As Diretrizes Curriculares Nacionais para o Ensino Médio (DCNEM) (BRASIL, 2013a) utilizam-se das mesmas concepções que a LDBEN, acrescentando como bases para o desenvolvimento do Ensino Médio a formação integral do educando, o trabalho e a pesquisa como princípios educativos e pedagógicos, a sustentabilidade ambiental, a educação em direitos humanos, a união entre educação e prática social - assim como entre teoria e prática no processo de ensino-aprendizagem -, e a integração de conhecimentos gerais e técnico-profissionais no contexto da interdisciplinaridade e contextualização. Os aspectos presentes na LDBEN e nas DCNEM, no que se refere à capacidade de adaptação às possíveis novas realidades encontradas quando fora da escola e contextualização, ressaltam a importância de dar atenção aos estudantes do Ensino Médio e à juventude e sua produção de significados neste contexto.

A inquietação decorrente das observações realizadas na disciplina de Estágio de Docência de Educação Física no Ensino Médio, onde os estagiários são convidados pelo professor orientador a pensar o ensino - e as aprendizagens - com centralidade no aluno, foi o que, inicialmente, motivou a realização desta revisão e, posteriormente, a realização de um estudo em andamento em nível de mestrado. Isso posto, entendemos que o estudante do Ensino Médio não é um sujeito "vazio", mas, construído histórica e socialmente e que carrega representações e visões de mundo desde suas experiências anteriores. Concordamos com Neira (2007) quando este apresenta que "juventude é produto de toda a história evolutiva anterior", evidenciando o quão transitório e polimorfo é esse período em que os estudantes do Ensino Médio se encontram e o quão importante é a escola incorporar as experiências e os saberes destes jovens no processo de ensino e aprendizagem.

A partir do exposto, este estudo buscou analisar a produção acadêmico-científica que aborda de maneira central a temática Educação Física no Ensino Médio e entender, a partir deste movimento analítico, como o tema juventude ganha visibilidade nas pesquisas voltadas à Educação Física escolar. Diante dessa delimitação, foi 
iniciado o processo de revisão bibliográfica a partir dos descritores: juventude, Educação Física escolar e Ensino Médio.

\section{DESCRIÇÃO METODOLÓGICA}

Empreendendo um esforço de avançar das considerações produzidas no estudo de Dias e Correia (2013), iniciamos a revisão elencando os seguintes critérios para a seleção dos periódicos: i) periódicos nacionais, que estivessem disponíveis de forma online e com buscador em seu portal; ii) periódicos da subárea da Educação Física classificados no Qualis da CAPES (Coordenação de Aperfeiçoamento de Pessoal de Nível Superior) de A2 à B5, com foco e escopos referentes à Educação Física, multi/interdisciplinar, ciências humanas e sociais; iii) periódicos da Área da Educação classificados no Qualis da CAPES de nível A1 a B1 com foco e escopos referentes às ciências humanas, ciências sociais, filosofia, psicologia, multi/interdisciplinar e Educação Física. A escolha dos periódicos de nível $A$ à $B$ da subárea da Educação Física se deu de forma a contemplar as escolhas de Dias e Correia (2013) em seu artigo de revisão, contudo, incluímos periódicos de nível A1 à B1 da Área da Educação em um esforço de avançar do estudo acima referido. De um universo de 2307 periódicos, foram selecionados 148 que atendiam aos critérios expostos anteriormente.

Os descritores utilizados para a busca nos periódicos de ambas as Áreas foram: juventude, Educação Física escolar e Ensino Médio. Tais terminologias foram escolhidas por entendermos a centralidade no problema de pesquisa que de nosso estudo em nível de mestrado. Posteriormente, os descritores foram combinados, com o intuito de refinar as buscas, da seguinte forma: juventude and Educação Fisica escolar and Ensino Médio; juventude and Educação Física escolar; e juventude and Ensino Médio. Apartir do entendimento de que "juventude" é o tema central do estudo, as combinações foram estabelecidas de forma que este descritor estivesse presente em todas. Quando as buscas não obtinham resultado com os descritores isolados, não era realizado o refinamento. Como resultado, foram compilados 90 artigos que abordavam juventude, Ensino Médio e Educação Física escolar. Destes, foi feito mais um refinamento que resultou em 25 artigos cuja temática estava centralizada em questões referentes à Educação Física escolar no Ensino Médio e 52 relacionados à juventude, totalizando 77 artigos. As buscas foram realizadas no período de 14/10/2014 à 05/11/2014.

\section{A Educação Física no ensino médio}

Dos 25 artigos compilados que tratam de Educação Física escolar no Ensino Médio destacamos os seguintes temas: aspectos motivacionais e participação nas aulas de Educação Física; dispensa e facultatividade da disciplina de Educação; conteúdos e saberes na Educação Física escolar; currículo/legislação da Educação Física escolar; planejamento participativo; proposta pedagógica; formação continuada; corpo/imagem corporal; artigo de revisão; Educação Física e ENEM; objetivo da Educação Física no Ensino Médio noturno; e representação da Educação Física para os estudantes. O quadro abaixo proporciona um panorama desses temas. 
V. $27, \mathrm{n}^{\circ} 46$, dezembro/2015

Quadro 1 - Educação Física no Ensino Médio.

\begin{tabular}{|c|c|c|}
\hline Tema & $N^{0}$ de artigos & Referências \\
\hline $\begin{array}{l}\text { Aspectos motivacionais e } \\
\text { de participação nas aulas de } \\
\text { Educação Física }\end{array}$ & 04 & $\begin{array}{l}\text { CHICATI, 2000; MARTINELLI et } \\
\text { al., 2006; PEREIRA; MOREIRA, } \\
\text { 2005; SILVA; COFFANI, } 2013\end{array}$ \\
\hline $\begin{array}{l}\text { Dispensa e facultatividade da } \\
\text { disciplina de Educação Física }\end{array}$ & 03 & $\begin{array}{l}\text { POSSEBON; CAUDURO, 2001; } \\
\text { SOUZA JÚNIOR; DARIDO, } \\
\text { 2009; FEITOSA et al., 2011 }\end{array}$ \\
\hline $\begin{array}{l}\text { Conteúdos e saberes na } \\
\text { Educação Física escolar }\end{array}$ & 03 & $\begin{array}{c}\text { PEREIRA; SILVA, 2004; } \\
\text { SCHNEIDER; BUENO, 2005; } \\
\text { ANDRADE; ANTUNES NETO, } \\
2008\end{array}$ \\
\hline $\begin{array}{l}\text { Currículo/legislação da } \\
\text { Educação Física escolar }\end{array}$ & 03 & $\begin{array}{c}\text { BRANDL, 2001; LIMA; } \\
\text { RODRIGUES, 2007; OLIVEIRA; } \\
\text { PANDA, } 2013\end{array}$ \\
\hline Planejamento participativo & 01 & SOUZA; FREIRE, 2008 \\
\hline Proposta pedagógica & 01 & MENEZES; VERENGUER, 2006 \\
\hline Formação continuada & 01 & $\begin{array}{c}\text { CAMPOS, GRUNENNVALDT; } \\
\text { COFFANI, } 2014\end{array}$ \\
\hline Corpo/imagem corporal & 02 & $\begin{array}{l}\text { SALVIVI; MYSKIW, 2009; } \\
\text { ASSARITTI; DAÓLIO, } 2011\end{array}$ \\
\hline Análise da produção científica & 01 & DIAS; CORREIA, 2013 \\
\hline Educação Física e ENEM & 02 & $\begin{array}{l}\text { FERNANDES; RODRIGUES; } \\
\text { NARDON, 2013; BELTRÃO, } \\
2014\end{array}$ \\
\hline $\begin{array}{l}\text { Objetivo da Educação Física } \\
\text { no Ensino Médio noturno }\end{array}$ & 01 & VARGAS; PEREIRA, 2012 \\
\hline $\begin{array}{l}\text { Representações de Educação } \\
\text { Física para os estudantes }\end{array}$ & 03 & $\begin{array}{c}\text { COSTA JÚNIOR; RIBEIRO, 2011; } \\
\text { WANDERLEY JÚNIOR; CEZAR, } \\
\text { 2013; FERREIRA, GRAEBNER; } \\
\text { MATIAS, } 2014\end{array}$ \\
\hline
\end{tabular}

Analisamos que há relativa diversidade nos artigos que trataram da aproximação entre os temas Educação Física e Ensino Médio. Essa diversidade pode ser entendida como uma dispersão de uma perspectiva mais focalizada em detrimento de outra, que contempla mais questões pontuais. Por exemplo, a temática apresentada em 
maior número de artigos é a relacionada a aspectos motivacionais e participação nas aulas de Educação Física, totalizando quatro artigos. Podemos estabelecer relação entre esta temática, a dispensa e a facultatividade da disciplina de Educação Física, que apresenta três publicações sobre o referido tema. Entendemos que pode haver uma inquietação em pesquisar temas que tratem mais do "chão da escola" - as aulas da disciplina de Educação Física - em função de atender aos fenômenos que adquirem maior visibilidade no cotidiano escolar e que este objeto de estudo é transversal, uma vez que as publicações são datadas de 2000 até 2013. Em contrapartida, as questões referentes ao professor de Educação Física, como formação continuada, proposta pedagógica e objetivos da Educação Física no Ensino Médio noturno, apareceram em menor número, totalizando apenas um artigo sobre cada um dos assuntos acima referidos, o que pode representar temas de menor visibilidade e problematização do que as temáticas abordadas anteriormente.

Encontramos os autores Jocimar Daólio, Valter Bracht, Suraya Darido, Mauro Betti, Castellani Filho e Eleonor Kunz entre as referências recorrentes nos artigos aqui elencados. Tal fato pode ser explicado por esses autores serem considerados referência no que diz respeito às discussões e formulações teóricas da Educação Física escolar pelo viés de uma perspectiva sociocultural crítica, que representa, em nossa análise, uma perspectiva hegemônica de compreensão e filiação política na focalização das questões sobre a Educação Física escolar no Brasil desde os anos 1990.

A partir do ano de 2011 o número de publicações apresentou um aumento significativo. Anterior a este ano havia um total de 13 publicações, sendo que nos anos de 2000, 2004 e 2007 houve apenas uma publicação por ano e nos anos de 2002, 2003 e 2010 não houve publicações acerca dessa temática. Os assuntos abordados nestas publicações eram diversos: motivação, participação, dispensas, conteúdos, etc. De 2011 a 2014 o total de publicações foi de 12 artigos, sendo três publicações em 2011, uma no ano de 2012, cinco publicações no ano de 2013 e três em 2014. Podemos assim perceber um aumento no que diz respeito a publicações na área da Educação Física escolar relacionada ao Ensino Médio.

Tal fato pode estar atrelado às discussões em torno da formulação das DCNEM (BRASIL, 2013a) e das implicações de suas teses e seus efeitos nas comunidades escolares. Entendemos que quando há reestruturações no campo da educação, das políticas públicas e das diretrizes para a educação no Brasil há, de modo consequente, mais reflexões e discussões na comunidade acadêmica. No caso da Educação Física no Ensino Médio, parece que havia certa acomodação da comunidade científica que não produzia artigos que remetessem à superação das limitações encontradas. Como advento de novas formas de pensar a Educação Física neste nível de ensino, pode ter ocorrido o "despertar" da atenção sobre as implicações e os efeitos das DCNEM (BRASIL, 2013a) na prática pedagógica dos professores de Educação Física. Isso fica visível nos dois artigos que tratam do Exame Nacional do Ensino Médio (RODRIGUES; NARDON, 2013; BELTRÃO, 2014) e nos três que tratam de centrar o foco nos significados dos alunos da Educação Física no Ensino Médio (COSTA JúNIOR; 
RIBEIRO, 2011; WANDERLEY JÚNIOR; CEZAR, 2013; FERREIRA, GRAEBNER; MATIAS, 2014).

\section{As juventudes}

O tema das juventudes é central em nossa investigação e eixo de potencialização da elaboração das DCNEM (BRASIL, 2013a). Entendemos que as DCNEM (idem) expõem a relevância que o trato com a juventude assume no Ensino Médio na medida em que apresentam um esclarecimento sobre "As juventudes", onde discorre sobre os sujeitos/estudantes do Ensino Médio. O documento concebe a juventude como uma

[...] condição sócio-histórico-cultural de uma categoria de sujeitos que necessita ser considerada em suas múltiplas dimensões, com especificidades próprias que não restritas às dimensões biológica e etária, mas que se encontram articuladas com uma multiplicidade de atravessamentos sociais e culturais, produzindo múltiplas culturas juvenis ou muitas juventudes (p. 155).

Ainda segundo o documento, compreender o jovem do Ensino Médio, partindo desta concepção de juventude, significa transpor uma noção de homogeneizar e naturalizar esses estudantes, além de tratá-los como uma categoria social (BRASIL, 2013a). Além de ser tratado na especificidade das DCNEM, sublinhamos a convergência com o que é apresentado nas Diretrizes Curriculares Nacionais para a Educação Básica (DCNEB) em relação à preocupação em perceber o estudante não como um sujeito vazio, mas sim repleto de experiências que pode intervir no seu processo de ensino-aprendizagem.

Exige-se, portanto, da escola, a busca de um efetivo pacto em torno do projeto educativo escolar, que considere os sujeitos-estudantes jovens como parte ativa de seus processos de formação, sem minimizar a importância da autoridade adulta. (BRASIL, 2013b, p.35)

Sobre a temática juventude em nossa revisão nos periódicos, foram compilados 52 artigos que relacionassem este tema à Ensino Médio e/ou Educação Física escolar. As publicações estabelecem relação entre juventude e os temas: identidade; escola; representações sociais; protagonismo juvenil; pertencimento; experiências sociais; cultura juvenil; artigo de revisão; conceituação; e políticas. 
Quadro 2 - Juventude

\begin{tabular}{|c|c|c|}
\hline Tema & $\mathrm{N}^{\circ}$ de artigos & Referências \\
\hline Identidade & 02 & $\begin{array}{l}\text { ARAÚJO, 2001; PAIS, 2009; SANTOS, } \\
\text { 2010. }\end{array}$ \\
\hline Escola & 09 & $\begin{array}{l}\text { BARRETO; MARTINEZ, 2011; CAMACHO, } \\
\text { 2004; DAYRELL, 2007; FRANCO, 2013; } \\
\text { MATTOS, 2013; SOUSA; DURAND, 2002; } \\
\text { TOMAZETTI ET AL., 2011; OLIVEIRA, } \\
\text { 2011; OLIVEIRA; TOMAZETTI, } 2012 .\end{array}$ \\
\hline Representações sociais & 13 & $\begin{array}{l}\text { ANDRADE; MEYER, 2014; BRAGHINI, } \\
\text { 2014; CARRANO, 2011; FREITAS; SOUZA, } \\
\text { 2014; GALINKIN; ALMEIDA; ANCHIETA, } \\
\text { 2012; LEITE; PÁTARO, 2013; LEÃO, } \\
\text { 2006; LEÃO; DAYRELL; REIS, 2011A; } \\
\text { LEÃO; DAYRELL; REIS, 2011B; NAKANO; } \\
\text { ALMEIDA, 2007; RAITZ; PETTERS, 2008; } \\
\text { SCHWERTNER; FISCHER, 2012; SILVA, } \\
\text { PELISSARI; STEIMBACH, 2013. }\end{array}$ \\
\hline Protagonismo juvenil & 05 & $\begin{array}{l}\text { FERRETTI; ZIBAS; TARTUCE, 2004; ZIBAS; } \\
\text { FERRETTI; TARTUCE, 2006; PÁTARO; } \\
\text { MORUZZI, 2011; ZIBAS, GONÇALVES, } \\
\text { 2005; ZYLBERBERG; BEZERRA, } 2013 .\end{array}$ \\
\hline Pertencimento & 01 & MIRANDA; FREITAS, 2013. \\
\hline Experiências sociais & 01 & TAKEUTI, 2012. \\
\hline Cultura Juvenil & 11 & $\begin{array}{l}\text { ALMEIDA, 2009; COSTA; PIRES, 2007; } \\
\text { DAYRELL, 2002; DAYRELL, 2003; DIAS; } \\
\text { MARCHI, 2012; LIMA, 2002; LIMA; LIMA, } \\
\text { 2012; MARTINS; CARRANO, 2011; } \\
\text { MORENO, 2009; SALES; PARAIISO, 2010; } \\
\text { PAIS, 2008; SPOSITO, } 2010 .\end{array}$ \\
\hline Artigo de revisão & 04 & $\begin{array}{l}\text { ANDRADE; PINHEIRO; ESTEVES, 2012; } \\
\text { GIL, 2011; PEREIRA, 2009; SCHIMIDT; } \\
\text { DURAND, } 2004 .\end{array}$ \\
\hline Conceituação & 03 & $\begin{array}{l}\text { AUGUSTO, 2005; MOREIRA, ROSÁRIO; } \\
\text { SANTOS, 2011; SZAPIRO; RESENDE, } 2010 .\end{array}$ \\
\hline Políticas & 01 & NOGUEIRA, 2011. \\
\hline
\end{tabular}

Do total de artigos encontrados, apenas cinco relacionavam-se com a área da Educação Física, sendo que destes, três estabelecem relações com a Educação Física escolar e dois que abordam a juven- tude ligada às temáticas de esporte e lazer. Iremos nos deter aos artigos que abordam a juventude relacionada com a Educação Física escolar, tendo em vista que este é o foco da nossa revisão. 
O estudo "Moda/indumentária em culturas juvenis: símbolos de comunicação e formação de identidades corporais provisórias em jovens do Ensino Médio", de Costa e Pires (2007), buscou evidenciar a existência dos grupos culturais de jovens nos espaços escolares - a partir de suas vestimentas - para que assim a escola pudesse promover formas de interação e de reconhecimento dos seus estudantes como sujeitos para além do espaço escolar, não se atendo a estabelecer normas, pois entendem que nos diversos espaços escolares os jovens expressam suas identidades, constituem seus grupos e se reconhecem neles. Apesar de o artigo não se referir à disciplina de Educação Física, destacamos que há um interesse de pesquisadores dessa área em investigar aspectos que dizem respeito à formação identitária dos jovens relacionando com questões ligadas à comunicação não verbal (linguagem corporal) como, por exemplo, a simbologia que as indumentárias podem vir a expressar sobre quem são e do que gostam os jovens contemporâneos.

Em "Juventude e internet: possibilidades de "criar" Educação Física", de Zylberberg e Bezerra (2013), é proposta uma nova forma de desenvolver questões ligadas à epistemologia da Educação Física, por intermédio da internet. O estudo é oriundo de uma dissertação de mestrado em Educação Física onde foi desenvolvido um projeto de mídia-educação que valorizasse diferentes linguagens e conteúdos elaborados pelos alunos de graducação do curso de licenciatura em Educação Física. Fica em evidência nessa pesquisa o trato com a influência que a mídia exerce em questões referentes a corpo, saúde, estética e como isso pode interferir nas aulas de Educação Física escolar, uma vez que e os estudantes têm contato direto com estes meios de comunicação; e o protagonismo juvenil, uma vez que os jovens graduandos desenvolvem um site de divulgação de pesquisas e referenciais contemporâneos da área da Educação Física, intensificando o seu potencial autoral. Vale ressaltar que os graduandos poderiam utilizar de suas experiências enquanto alunos de Educação Física escolar durante o processo de criação do projeto, levando assim em consideração a experiência desses sujeitos.

O estudo acima citado trata de juventude e da Educação Física escolar em uma perspectiva diferente, uma vez que trata da formação de futuros professores de Educação Física e os entende como sujeitos jovens construídos historicamente, levando em consideração as suas experiências para assim estimular o protagonismo dos mesmos, um ponto muito importante a ser desenvolvido com profissionais que trabaIharão com o público jovem.

Lima e Lima (2012), em seu artigo "As culturas juvenis e a cultura corporal de movimento: em busca de interlocução", buscam promover uma interação entre culturas juvenis, cultura corporal de movimento e a Pedagogia de Paulo Freire, visando a indicação de metodologias que favoreçam esta pedagogia no contexto escolar. Os autores entendem que as aulas de Educação Física devem propiciar novos espaços de diálogo e que, desse modo, possibilitam que os jovens se desenvolvam em todas as dimensões. Sendo assim as aulas de Educação Física promovem novos "[...] espaços de vivências significativas, de descobertas, de criações, de debates, de produção de conhecimento e, principalmente, de reflexão crítica sobre a experiência [...] (LIMA; LIMA, 2012, p. 230). Este artigo é o 
que mais se aproxima ao foco da revisão e, pontualmente, de nosso estudo sobre a relação entre as representações de juventude, a Educação Física e o Ensino Médio, pois revela como a disciplina de Educação Física no Ensino Médio pode ser importante na formação crítica e integral do aluno quando as experiências, interesses e necessidades desses são levadas em consideração. Há uma preocupação em mostrar como essa disciplina pode influenciar significativamente na formação desses jovens, não sendo vista apenas como um horário de lazer, de fruição, mas como um componente curricular obrigatório que vem a gerar conhecimentos específicos à sua Área e em acordo com o contexto de seus estudantes. Entendemos que estas considerações são relevantes pois nos auxiliam na compreensão sobre a diversidade da cultura juvenil e os lugares e tempos para uma Educação Física crítica que potencialize a formação de um cidadão crítico e autônomo.

\section{CONSIDERAÇÕES FINAIS}

Podemos perceber que um aspecto significativo e comum aos estudos de Lima e Lima (2012), Zylberberg e Bezerra (2013) e Costa e Pires (2007) é a convergência entre a Educação Física escolar e o tema juventudes, que se traduz na cultura juvenil. A cultura juvenil parece adquirir significativa visibilidade nos artigos revisados. Parece-nos que as interpretações sobre ou a partir da focalização sobre as culturas juvenis podem ser reveladoras de um interesse pelo que é compartilhado pelos jovens na escola, pela produção de sentidos e significados que configuram suas relações com a escola, com o Ensino Médio e com a Educação Física, sobretudo, talvez pelo fato de posicionar estes atores sociais na condição de sujeitos representativos no ordenamento dos poderes na escola e na sociedade, elemento identificado nas Diretrizes recentemente promulgadas para o Ensino Médio.

Nosso interesse é compreender como as DCNEM (BRASIL, 2013a) implicam as relações que se tecem no cotidiano dos jovens que cursam o Ensino Médio e, especificamente, como eles mesmos interpretam os significados do que compartilham na cultura juvenil. Da mesma forma, pelas representações apresentadas pela temática moda/indumentária, ou, ainda, através da internet - local onde os jovens se comunicam, expressam suas ideias, compartilham sentimentos e têm seus grupos de interesses, onde estão conectados/interligados constantemente. Neste sentido, entendemos que a questão do protagonismo, formação de identidade e pertencimento estão presentes nos estudos de Lima e Lima (2012), Zylberberg e Bezerra (2013) e Costa e Pires (2007) de maneira expressiva, uma vez que eles afirmam a importância de levar em consideração a experiência dos jovens estudantes e de seus contextos e estimulam o diálogo como método para desenvolver tais questões.

No que se refere ao número de publicações, do ano de 2001 a 2010 a média foi de 2,4 artigos publicados por ano, tendo um montante de 24 publicações durante esse período. Já no período compreendido entre 2011 a 2014 tivemos o total de 27 publicações referentes ao tema juventude, aumentando assim a média para 6,7 publicações por ano. Assim como foi verificado nas publicações referentes à Educação Física escolar e Ensino Médio, no ano de 2011 o número de publicações relativas à temática 
juventude aumentou consideravelmente, tendo um total de 11 publicações somente neste ano.

Podemos entender que este aumento de publicações voltadas ao tema juventude tenha se originado da problematização deste tema nas DCNEB, publicadas em 2010, onde Miguel Arroyo (2000 apud BRASIL, 2013b) defende que professores dos anos finais do Ensino Fundamental e do Ensino Médio, devem ser especialistas em adolescência e juventude, entendendo que assim serão educadores responsáveis por esses sujeitos e pela qualidade de sua relação com o mundo. Segundo as DCNEB, "tal posição implica um redimensionamento dos cursos de licenciatura e da formação continuada desses profissionais" (BRASIL, 2013b, p.58).

As publicações, em sua maioria, estão concentradas em periódicos da Área da Educação, apesar de também haver artigos publicados em periódicos ligados às Áreas da Psicologia, Educação Física e Ciências Sociais. Podemos notar que todas as áreas citadas estabelecem - de alguma forma - relação com a área da Educação, por essa ser uma área "guarda-chuva" que abrange as demais e, talvez por isso, haja um maior interesse por parte dos pesquisadores em publicar estudos ligados ao tema juventude em periódicos dessa Área - onde pesquisadores de diversas áreas acessam -, buscando assim dar uma maior visibilidade às suas pesquisas do que quando publicada em periódicos específicos de suas áreas. Para finalizar, talvez possamos interpretar que ainda ocorre um processo de "migração" das publicações dos pesquisadores da Área de Educação Física que buscam compreender os fenômenos da escola do ponto de vista sociocultural dos periódicos dessa Área para a Área da Educação, onde encontram acolhimento para interpretações que superam o determinismo analítico de causa e efeito positivista, "hipertrofiados" pela imposição do modelo baseado no sistema produtivista próprio dos estudos biomédicos clássicos que têm dominado a Área 21 da CAPES.

\section{REFERÊNCIAS}

ANDRADE, R. C. B; ANTUNES NETO, J. As aulas de Educação Física no Ensino Médio: implicações nas discussões sobre as temáticas aprendizagem e qualidade de vida. Conexões: revista da Faculdade de Educação Física da UNICAMP, Campinas, v. 6, n. especial, p. 389-396, jul. 2008.

ANDRADE, E. R; PINHEIRO, D; ESTEVES, L. C. G. Juventude como tema na Educação, nas Ciências Sociais e no Serviço Social. Em Aberto, Brasília, v. 25, n. 87, p. 193-204, jan./jun. 2012.

ANDRADE, S. S; MEYER, D. E. Juventudes, moratória social e gênero: flutuações identitárias e(m) histórias narradas. Educar em Revista, Curitiba, Edição Especial, n. 1, p. 85-99, 2014.

ARAÚJO, C. As marcas da violência na constituição da identidade de jovens da periferia. Educação e Pesquisa, São Paulo, v. 27, n. 1, p. 141-160, jan./ jun. 2001.

ASSARITTI, D. S; DAÓLIO, J. A intervenção do professor de Educação Física junto a aluno do Ensino Médio sobre o fenômeno do culto ao corpo. Conexões: revista da Faculdade de Educação Física da UNICAMP, Campinas, v. 9, n. 1, p. 67-91, jan./abr. 2011. 
AUGuSTO, M. H. O. Retomada de um legado intelectual: Marialice Foracchi e a sociologia da juventude. Tempo Social, São Paulo, v. 17, n. 2, p. 11-33, 2005.

BARRETO, M. C. A; MARTINEZ, S. A. Os jovens do ensino médio regular e da educação de jovens e adultos: suas vozes e experiências em meio ao ensino noturno em análise. Revista Teias, Rio de Janeiro, v. 12 , n. 26 , p. 83-114, set./ dez., 2011.

BELTRÃO, J. A. A Educação Física na escola do vestibular: as possíveis implicações do ENEM. Movimento, Porto Alegre, v. 20, n. 2, p. 819-840, abr./jun., 2014.

BRAGHINI, K. M. Z. Revista Realidade: Edição especial "A Juventude Brasileira, hoje". Setembro 1967. Educar em Revista, Curitiba, n. 51, p. 311-320, jan./mar., 2014.

BRANDL, C. E. H. O novo Ensino Médio e a Educação Física. Caderno de Educação Física, Marechal Cândido Rondon, v. 3, n. 2, p. 79-87, 2001.

BRASIL. República Federativa do Brasil. Lei no 9.394: Estabelece as Diretrizes e Bases da Educação Nacional. Brasília, 1996.

BRASIL. Ministério da Educação. Resolução $\mathrm{n}^{\circ} 2$, de 30 de Janeiro 2012: Define Diretrizes Curriculares Nacionais para o Ensino Médio. In: BRASIL. Ministério da Educação. Secretaria de Educação Básica. Diretrizes Curriculares Nacionais para a Educação Básica. Brasília, 2013.

BRASIL. Ministério da Educação. Resolução $n^{\circ} 4$, de 13 de Julho de 2010: Define Diretrizes Curriculares Nacionais Gerais para a Educação Básica. In: BRASIL. Ministério da Educação. Secretaria de Educação Básica. Diretrizes Curriculares
Nacionais para a Educação Básica. Brasília, 2013.

CAMACHO, L. M. Y. A invisibilidade da juventude na vida escolar. Perspectiva, Florianópolis, v. 22, n. 02, p. 325-343, jul./dez. 2004.

CAMPOS, J. R. C; GRUNENNVALDT, J. T; COFFANI, M. C. R. S. Educação Física e Ensino Médio: da regulação instituída para a construção permanente da experiência. Conexões: revista da Faculdade de Educação Física da UNICAMP, Campinas, v. 12, n. 2, p. 13-36, abr./jun. 2014.

CARRANO, P. Jovens, escolas e cidades: desafios à autonomia e à convivência. Revista Teias, Rio de Janeiro, v. 12, n. 26, p. 07-22, set./dez., 2011.

CHICATI, K. C. Motivação nas aulas de Educação Física no Ensino Médio. Revista da Educação Física/UEM, Maringá, v. 11, n. 1, p. 97-105, 2000.

COSTA, A. G; PIRES, G. L. Moda/ indumentária em culturas juvenis: símbolos de comunicação e formação de provisórias em jovens do Ensino Médio identidades corporais. Conexões: revista da Faculdade de Educação Física da UNICAMP, Campinas, v. 5, n.1, p. 51-66, 2007.

COSTA JÚNIOR, E. F; RIBEIRO, C. H. $\mathrm{V}$. Representações dos alunos da $2 \mathrm{a}$ série do Ensino Médio sobre as aulas de Educação Física no CETEP-Barreto. Corpus et Scientia, ano 7, vol. 7, n. 2, p. 138-144, novembro, 2011.

DAYRELL, J. O rap e o funk na socialização da juventude. Educação e Pesquisa, São Paulo, v. 28, n. 1, p. 117-136, jan./ jun. 2002.

DAYRELL, J. O jovem como sujeito social. Revista Brasileira de Educação, Rio de 
Janeiro, n. 24, p. 40-52, set. /out. /nov./ dez. 2003.

DAYRELL, J. A escola "faz" as juventudes? Reflexões em torno da socialização juvenil. Educação e Sociedade, Campinas, v. 28, n. 100, edição especial, p. 1105-1128, out. 2007.

DIAS, D. C; MARCHI, R. C. Um estudo sobre "culturas juvenis" na escola. Atos de Pesquisa em Educação, Blumenau, v. 7, n. 4, p. 1053-1080, dez. 2012.

DIAS, D. I; CORREIA, W. R. A Educação Física no Ensino Médio como objeto de estudo da produção acadêmicocientífica nos periódicos nacionais. Revista Brasileira de Educação Física e Esporte, São Paulo, v. 27, n. 2,p. 277287, abr,/jun. 2013.

FEITOSA, W. M. N; TASSITANO, R. M; TENÓRIO, M. C. M; ALBUQUERQUE, A; GUIMARÃES, F. J. P. S; LIMA NETO, A. J. Aulas de Educação Física no Ensino Médio da rede pública estadual de caruaru: componente curricular obrigatório ou facultativo? Revista da Educação Física/UEM, Maringá, v. 22, n. 1, p. 97-109, 1. trim. 2011.

FERNANDES, A; RODRIGUES, H. A; NARDON, T. A. A inserção dos conteúdos de Educação Física no ENEM: entre a valorização do componente curricular e as contradições da democracia. Motrivivência, Florianópolis, ano 25, n. 40, junho. 2013.

FERREIRA, M. L. S; GRAEBNER, L; MATIAS, T. S. Percepção de alunos sobre as aulas de Educação Física no Ensino Médio. Pensar a Prática, Goiânia, v. 17, n. 3, p. 734-750, jul./set. 2014.

FERRETTI, C. J; ZIBAS, D. M. L; TARTUCE, G. L. B. P. Protagonismo juvenil na literatura especializada e na reforma do
Ensino Médio. Cadernos de Pesquisa, São Paulo, v. 34, n. 122, p. 411-423, maio/ago. 2004.

FRANCO, F. F. O professor e os jovens: a relação professor-aluno e o ambiente de trabalho. Atos de Pesquisa em Educação, Blumenau, v. 8, n. 3, p. 9981018, set./dez. 2013.

FREITAS, M. F. Q; SOUZA, J. PAIVA, A. R. (Org.). Juventude, cultura cívica e cidadania. Rio de Janeiro: Garamond, 2013. Educar em Revista, Curitiba, n. 53, p. 313-318, jul./set., 2014.

GALINKIN, A. L; ALMEIDA, A. M. O; ANCHIETA, V. C. C. Representações sociais de professores e policiais sobre a juventude e violência. Paidéia, Ribeirão Preto, v. 22, n. 53, p. 365-374, set./ dez., 2012.

GIL, C. Z. V. Jovens e juventudes: Consensos e desafios. Educação, Santa Maria, v. 36, n. 1, p. 25-42, jan./abril, 2011.

GONÇALVES, H. S. Juventude brasileira, entre a tradição e a modernidade. Tempo Social, São Paulo, v. 17, n. 2, p. 207-219, 2005.

LEÃO, G.M. P. Experiências da desigualdade: os sentidos da escolarização elaborados por jovens pobres. Educação e Pesquisa, São Paulo, v. 32, n. 1, p. 31-48, jan./ abr. 2006.

LEÃO, G; DAYRELL, J. T; REIS, J. B. Jovens olhares sobre a escola do Ensino Médio. Caderno Cedes, Campinas, v. 31, n. 84, p. 253-273, maio/ago. 2011a.

LEÃO, G; DAYRELL, J. T; REIS, J. B. Juventude, projetos de vida e Ensino Médio. Educação e Sociedade, Campinas, v. 32, n. 117, p. 1067-1084, out./dez. 2011b.

LEITE, L. L; PÁTARO, C. S. O. Diferenças de gênero e juventude. Um estudo a 
partir das vivências de estudantes de Ensino Médio do município de Campo Mourão - PR. Revista Ibero-Americana de Estudos em Educação, Araraquara, v. 8, n. 2, 2013.

LIMA, A. Funkeiros, timbaleiros e pagodeiros: Notas sobre juventude e música negra na cidade de Salvador. Caderno Cedes, Campinas, v. 22, n. 57, p. 77-96, ago.2002.

LIMA, J. L; RODRIGUES, R. Análise do profissional de Educação Física e sua correlação com as diretrizes curriculares do Ensino Médio. Educação Física em Revista, Brasília, v. 1, n. 1, p. 1-20, 2007.

LIMA, M. R. C; LIMA, J. M. As culturas juvenis e a cultura corporal de movimento: em busca de interlocução.

Revista Teias, Rio de Janeiro, v. 13, n. 27, p. 219-241, jan./abr., 2012.

MARTINELLI, C. R; MERIDA, M; RODRIGUES, G. M; GRILLO, D. E; SOUZA, J. X. Educação Física no Ensino Médio: motivos que levam as alunas a não gostarem de participar das aulas as alunas a não gostarem de participar das aulas. Revista Mackenzie de Educação Física e Esporte, São Paulo, v. 5, n. 2, p. 13-19, 2006.

MARTINS, C. H. S; CARRANO, P. C. R. A escola diante das culturas juvenis: reconhecer para dialogar. Educação, Santa Maria, v. 36, n. 1, p. 43-56, jan./ abr., 2011.

MATTOS, R. A. Pensando o mal-estar na/da educação através da compreensão das 'juventudes líquidas' contemporâneas. Revista Eletrônica Pesquiseduca, Santos, v. 05, n. 10, p. 295-309, jul./dez. 2013. MENEZES, R; VERENGUER, R. C. G. Educação Física no Ensino Médio: o sucesso de uma proposta segundo os alunos proposta segundo os alunos. Revista Mackenzie de Educação Física e Esporte, São Paulo, v. 5, n. Especial, p. 99-107, 2006.

MIRANDA, S. R; FREITAS, D. P. Brasil sob o signo da memória: Notas sobre jovens, nação e nacionalismos. Educação em Revista, Belo Horizonte, v. 29, n. 2, p. 143-174, jun. 2013.

MOARES, A. C; ALMEIDA JÚNIOR, A. S; OLIVEIRA, C. M; SANTOS, K. C; BRASILEIRO, L. T; OLIVEIRA, N. R. C. Conhecimentos de Educação Física. In: BRASIL. Ministério da Educação. Orientações Curriculares para o Ensino Médio - Linguagens, Códigos e suas Tecnologias. Brasília: MEC. Volume:1, 2008. p. 213- 238.

MOREIRA, J. O; ROSÁRIO, A. B; SANTOS, A. P. Juventude e adolescência: considerações preliminares. PSICO, Porto Alegre, v. 42, n. 4, p. 457-464, out./dez., 2011.

MORENO, R. C; ALMEIDA, A. M. F. O engajamento político dos jovens no movimento hip-hop. Revista Brasileira de Educação, Rio de Janeiro, v. 14, n. 40, jan./abr. 2009.

NAKANO, M; ALMEIDA, E. Reflexões acerca da busca de uma nova qualidade da educação: relações entre juventude, educação e trabalho. Educação e Sociedade, Campinas, v. 28, n. 100, edição especial, p. 1085-1104, out. 2007.

NOGUEIRA, Q. W. C. Esporte, desigualdade, juventude e participação. Revista Brasileira de Ciências do Esporte, Florianópolis, v. 33, n. 1, p. 103-117, jan./mar 2011.

OLIVEIRA, A. M. Entre impuros e estranhos: o pensamento de Zygmunt Bauman e a 
lógica escolar do Ensino Médio. Revista Espaço Acadêmico, ano 11, n. 25, p. 1-9, outubro, 2011.

OLIVEIRA, A. M; TOMAZETTI, E. M. Sobre a condição juvenil na escola contemporânea: cenários de uma crise. Atos de Pesquisa em Educação, Blumenau, v. 7, n. 1, p. 106-121, jan./ abr. 2012.

OLIVEIRA, A. A. S. B; PANDA, M. D. J. A Educação Física e a proposta pedagógica para o Ensino Médio politécnico - SE/ RS. Biomotriz, Cruz Alta, v. 7, n. 2, dez. 2013.

PAIS, J. M. Máscaras, jovens e "escolas do diabo". Revista Brasileira de Educação, Rio de Janeiro, v. 13, n. 37, p. 7-21, jan./ abr. 2008.

PAIS, J. M. A juventude como fase de vida: Dos ritos de passagem aos ritos de impasse. Saúde Soc. São Paulo, v.18, n. 3, p. 371-381, 2009.

PÁTARO, C. S. O; MORUZZI, A. B. Culturas juvenis e currículo: valorização dos sujeitos jovens no trabalho escolar. Revista Teias, Rio de Janeiro, v. 12, n. 26, p. 61-81, set./dez., 2011.

PEREIRA, F. M; SILVA, A. C. Sobre os conteúdos da Educação Física no Ensino Médio em diferentes redes educacionais do Rio Grande do Sul. Revista da Educação Física/UEM, Maringá, v. 15, n. 2, p. 67-77, 2. sem. 2004.

PEREIRA, R. S; MOREIRA, E. C. A participação dos alunos do Ensino Médio em aulas de Educação Física: algumas considerações. Revista da Educação Física/UEM, Maringá, v. 16, n. 2, p. 121-127, 2. sem. 2005.

PEREIRA, M. A. Juventude, experiência e conhecimento em Walter Benjamin: para um novo saber da educação.
Currículo sem Fronteiras, Revista Digital, v. 9, n. 2, p. 242-257, jul./dez. 2009.

POSSEBON, M; CAUDURO, M. T. Educação Física no Ensino Médio: o lado oculto das dispensas. Kinesis, Santa Maria, n. 25, p. 129-147, 2001.

RAITZ, T. R; PETTERS, L. C. F. Novos desafios dos jovens na atualidade: trabalho, educação e família. Psicologia

\& Sociedade, Belo Horizonte, v. 20, n. 3, p. 408-416, 2008.

SALES, S. R; PARAÍSO, M. A. Escola, Orkut e juventude conectados: falar, exibir, espionar e disciplinar. Pro-Posições, Campinas, v. 21, n. 2 (62), p. 225-242, maio/ago. 2010.

SALVIVI, L; MYSKIW, M. As manipulações do corpo na representação da imagem social de alunas nas aulas de Educação Física. Pensar a Prática, Goiânia, v. 12, n. 3, p. 1-11, set./dez. 2009.

SANTOS, E. S. Atividades de lazer de estudantes do Ensino Médio de Canoas/ RS. Revista Arquivos em Movimento, Rio de Janeiro, v.6, n.1, p.5-25, jan./ jun.2010.

SCHMIDT, M. A; DURAND, O. C. S. Juventude, juventudes: processos e espaços educativos. Perspectiva, Florianópolis, v. 22, n. 02, p. 291-296, jul./dez. 2004.

SCHNEIDER, O; BUENO, J. G. S. A relação dos alunos com os saberes compartilhados nas aulas de Educação Física. Movimento, Porto Alegre, v. 11, n. 1, p. 23-46, jan./abril, 2005.

SCHWETNER, S. F; FISCHER, R. M. B. Juventudes, conectividades múltiplas e novas temporalidades. Educação em Revista, Belo Horizonte, v. 28, n. 01, p. 395-420, mar. 2012. 
SILVA, F. M; COFFANI, M. C. R. S. O lugar da Educação Física no Ensino Médio: entre a presença e ausência do aluno. Conexões: revista da Faculdade de Educação Física da UNICAMP, Campinas, v. 11, n. 4, p. 164-185, out./ dez. 2013.

SILVA, M. R; PELISSARI, L. B; STEIMBACH, A. A. Juventude, escola e trabalho: permanência e abandono na educação profissional técnica de nível médio. Educação e Pesquisa, São Paulo, v. 39, n. 2, p. 403-417, abr./jun. 2013.

SOUSA, J. T. P; DURAND, O. C. Experiências educativas da juventude: entre a escola e os grupos culturais. Perspectiva, Florianópolis, v. 20, n. especial, p. 163-181, jul./dez., 2002. SOUZA, A. G; FREIRE, E. S. Planejamento participativo e Educação Física: envolvimento e opinião dos alunos do Ensino Médio. Revista Mackenzie de Educação Física e Esporte. São Paulo, v. 7, n. 3, p. 29-36, 2008.

SOUZA JÚNIOR, O. M; DARIDO, S. C. Dispensas das aulas de Educação Física: apontando caminhos para minimizar os efeitos da arcaica legislação. Pensar a Prática, Goiânia, v. 12, n. 2, p. 1-12, maio/ago. 2009.

SPOSITO, M. P. Transversalidades no estudo sobre jovens no Brasil: educação, ação coletiva e cultura. Educação e Pesquisa, São Paulo, v.36, n. especial, p. 95-106, 2010.

SZAPIRO, A. M; RESENDE, C. M. A. Juventude: etapa da vida ou estilo de vida? Psicologia \& Sociedade, Belo Horizonte, v. 22, n. 1, p. 43-49, 2010.

TAKEUTI, N. M. Paradoxos societais e juventude contemporânea. Estudos de Psicologia, Natal, v. 17 , n. 3, p. 427434, set./dez. 2012.

TOMAZETTI, E. M; RAMOS, N. V; SALVA, S; OLIVEIRA, A. M; SCHLICKMANN, V. Entre o "gostar" de estar na escola e a invisibilidade juvenil: Um estudo sobre jovens estudantes de Santa Maria, RS. Educação, Santa Maria, v. 36, n. 1, p. 79-94, jan./abril, 2011.

VARGAS, J. E. N; PEREIRA, F. M. Os objetivos da Educação Física no Ensino Médio noturno. Biomotriz, Cruz Alta, v. 6, n. 1, p. 88-101, jun. 2012.

WANDERLEY JÚNIOR, E. S; CEZAR, E. H. A. A Educação Física como disciplina formadora no Ensino Médio/técnico: investigando a sua relevância. Caderno de Educação Física e Esporte, Marechal Cândido Rondon, v. 11, n. 2, p. 49-59, jul./dez. 2013.

ZIBAS, D. M L; FERRETTI, C. J; TARTUCE, G. L. B. P. Micropolítica escolar e estratégias para o desenvolvimento do protagonismo juvenil. Cadernos de Pesquisa, v. 36 , n. 127 , p. 51-85, jan./ abr. 2006.

ZYLBERBERG, T. P; BEZERRA, F. L. L. Juventude e internet: possibilidades de "criar" Educação Física. Atos de Pesquisa em Educação, Blumenau, v. 8, n. 1, p. 182-208, jan./abr. 2013. 
THE PRODUCTION ABOUT YOUTH IN JOURNALS OF EDUCATION AND PHYSICAL EDUCATION

\begin{abstract}
This review article aims to analyze the youth theme approach in national journals of the areas of Education and Physical Education. 148 journals were analyzed regarding these Areas. We found that there is more production on the youth issue in the Area of Education, with only 03 articles, a total of 52, referred to the school physical education. From this, we interpret that the low production on this subject may be indicative of little questioning on the topic of youth and also a little asymmetry between the production and the legal frameworks of national education that highlight the importance of youth culture that is shared in physical education classes in basic education schools.
\end{abstract}

Keywords: Physical Education; Education; Article Review; Adolescent

\title{
LA PRODUCCIÓN ACERCA JUVENTUd EN REVISTAS DE LA EDUCACIÓN Y EDUCACIÓN FÍSICA
}

\section{RESUMEN}

Este artículo de revisión tiene como objetivo analizar el enfoque temático de la juventud en revistas nacionales de las áreas de Educación y Educación Física. Fueron analizados 148 revistas con respecto a estas Áreas. Hemos encontrado que hay un aumento de la producción en el tema de la juventud en la Área de Educación, con sólo 03 artículos, un total de 52, que se refiere a la educación física escolar. A partir de este, interpretamos que la baja producción en este tema puede ser indicativo de poco cuestionamiento sobre el tema de la juventud y también una asimetría entre la baja producción y los marcos legales de la educación nacional que ponen de relieve la importancia de la cultura juvenil que es compartida en las clases de educación física en las escuelas de educación básica.

Palabras clave: Educación Física; Educación; Artículo de Revista; Adolescente

Recebido em: julho/2015 Aprovado em: novembro/2015 